Pre-publications version of Chapter 3 in J Courvisanos, J Doughney and A Millmow (eds), Reclaiming Pluralism in Economics. London: Routledge, 2016, pp. 32-46.

\title{
Consistency in Pluralism and the Role of Microfoundations ${ }^{\mathrm{i}}$
}

\author{
Sheila Dow
}

\section{Introduction}

As a highly-respected chronicler of the state of modern economics and its history, and in particular in his promotion of pluralism in economics, John King provides ample material on which to base a further consideration of pluralism. It is challenging to single out any particular publications by John King, given the breadth and depth of his knowledge, and the careful analysis and bold argument he consistently displays in his work. Nevertheless, for the purposes of this paper, I focus on two papers which I have found particularly striking. A central piece of work for the focus of this volume is his discussion of the case for pluralism (King 2002). My purpose here is to relate that paper to another striking paper arguing against the significant drive within modern economics to specify microfoundations. I first heard this argument as a paper presentation at the IMK/FMM annual conference in Berlin in 2008 and then at a symposium on microfoundations at SOAS in 2009; since then he has published a more full account of his analysis of microfoundations in his 2012 monograph. Both papers were thought provoking, in terms of reflection on the two conceptual areas and on the different stances on them which were revealed. The discussion here is a set of reflections provoked by these papers.

The first paper considers three different arguments for pluralism within heterodox economics. It is important to establish at the start what is being meant by pluralism, since it can refer to any of the levels of philosophy, methodology and theory (see further Dow 1997). The three arguments refer 
primarily to the philosophical level, i.e. methodological pluralism - the acceptance of, and respect for, a range of methodological approaches on the grounds that no one approach can be demonstrated to be best given the nature of the subject matter. The meaning at the level of methodology is pluralist methodologies, i.e. particular approaches which advocate use of a range of methods. Methodological pluralism could in principle allow for a methodological approach which advocates only one method. But the prime case of such a methodology is the mainstream insistence on mathematical formalism, which takes a methodological monist approach. There is further theoretical pluralism, i.e. a range of theories. Since methodological approach is regarded in mainstream discourse as settled, this is usually the meaning of pluralism employed there. While there is a variety of theories within mainstream economics, nevertheless they are all conditioned by the shared ontology, epistemology and methodology by which mainstream economics is defined (Dow 2007).

While methodological pluralism involves acceptance that there will be a range of approaches to economics, it does not mean that any economist should use several approaches simultaneously, since to do so would in effect mean developing a new, synthetic approach. Rather it means that any economist should be sufficiently methodologically aware to be able to make the case for her own approach relative to others. No approach can be definitively demonstrated to be superior, but that does not mean that argument for one's own approach cannot be forceful. Heterodox economists are inevitably methodologically aware in that the case has to be made relative to the mainstream approach. Nevertheless there are some apparent expressions of monism in heterodoxy as a challenge to pluralism (see Dow 2008 for a flavour of the debate). At the very start of the pluralism paper, John King nails his colours firmly to the mast: 'Is there a single correct alternative to neoclassical economics? The purpose of this short paper is to suggest that there is not'. 
King (2002) focuses on the Sraffian, Post Keynesian and institutionalist arguments for pluralism, all of which are based on an ontology which defies any prospect of one general overarching theory or theoretical approach. But all have exclusions from this openness to different approaches. These exclusions are different but overlapping: Sraffians exclude neoclassical economic theory, Post Keynesians exclude exclusive use of mathematical formalism while institutionalists exclude any theory which purports to be general. All the arguments about exclusion involve some application of the principle of consistency, although at different levels. Sraffians point to theoretical inconsistency in neoclassical economics with respect to capital, while Post Keynesians and institutionalists focus more on inconsistencies between ontology and epistemology in criticising methodological and theoretical exclusiveness, respectively. But is it inconsistent for a pluralist to exclude methodologies or theories in this way, or is this just one implication of structured pluralism? John King's paper concludes that differences between pluralists can be overcome by communication, but how far is communication between different approaches itself open to inconsistencies of meaning?

The second paper similarly pulls no punches, demonstrating further differences among heterodox economists, given that many, like orthodox economists, employ the concept of microfoundations which he so effectively critiques, drawing on the philosophy literature. Again consistency is a continuing theme. The case for microfoundations has been based on the view that macroeconomics and microeconomics should be consistent, although John King goes on to explain that neither need be foundational to the other. He argues however that, while some inconsistency between the two levels is to be expected, nevertheless one aim should be to reduce inconsistency. Further, John King argues not only for theory to be consistent with the economist's social and philosophical approach, but that this approach should be foundational. Here we see an echo of the arguments for 
pluralism in the earlier paper, based on consistency between theory on the one hand and ontology and epistemology on the other.

While the concept of consistency arises in both papers, it is worth reflecting further on what exactly is being meant by this term too. The purpose of this paper is to try to unpack the different ways in which the consistency concept applies to both papers. We consider consistency at three levels, but in the reverse order to the outline of pluralism above: the theoretical, methodological and philosophical levels. We therefore start with theoretical consistency, which then raises the issue at the methodological level of the system of logic within which consistency is being applied, in particular whether it is classical logic or human logic. Next we consider philosophical consistency, between ontology, epistemology, methodology and theory. In the process we consider further John King's argument for social and philosophical foundations. We then consider the issue of consistency with respect to communication. This involves consideration of the concept of vagueness. Finally we review the implications of this discussion of consistency for the future direction of heterodox economics, and in particular for Post Keynesian economics.

King (2008) highlights the powerful role of metaphor in the history of ideas right at the start of the microfoundations paper. In the process of the exploration here of consistency in relation to pluralism and microfoundations, we will bear in mind the powerful metaphor which King develops from Geoff Harcourt's account of Post Keynesian methodology: 'horses for courses' (see further Harcourt 1987, 1996). This metaphor captures the idea that methodology should reflect the problem at hand and the real context in which it arises. There is disagreement between the three heterodox groups represented in the pluralism paper in terms of their respective views on formalism, with openness to different methods for specific problems being greatest for 
institutionalists and least for Sraffians; this can be understood as a different choice as to the appropriate type of horse for a particular course.

King (2002) points out that the need for some consistency puts some limits on the horses. With respect to theoretical consistency, he points to inconsistencies in mainstream economics, concluding that each horse must 'have four legs and a jockey and proceed anti-clockwise around the course' and further that 'all four legs must be pointing in the same direction'. But his argument that more theoretical consistency is desirable requires further reflection on what exactly is meant by that. At risk of torturing the metaphor, we will see how we might develop it further as the discussion proceeds. We return to an early statement of the 'horses for courses' position in the final section on Post Keynesian economics.

\section{Theoretical Consistency}

The argument for theoretical consistency arises in both papers. It is central to the microfoundations paper, where mainstream economics is shown to have been driven by a commitment to increase consistency between the micro and macro levels of analysis - indeed to make the two levels of theory perfectly consistent. John King's main argument is against requiring the micro level to be established prior to the macro level (or indeed vice versa), such that one level provides the foundation for the other. 'Foundations, to repeat, must come first. The constitutive nature of the foundational metaphor is most evident, and most damaging, here' (King 2008: 36, emphasis in original). 
A secondary argument is against giving priority in economics practice to the exercise of promoting consistency. Nevertheless, other things being equal, increased consistency is to be pursued:

'The position that I shall be defending is this: consistency between microeconomics and macroeconomics is desirable, but it does not entail that the former is the foundation of the latter. In more general terms, the fact that there is (or may be, or appears to be) some inconsistency between two related bodies of knowledge, A and B, does not entail that A must become the foundation for B, or for that matter that B must become the foundation for A' (King 2008: 3-4).

Keynesian economics has been criticised by the mainstream on the grounds of lack of consistency between the macro and micro levels. It has therefore been particularly appealing to heterodox economists to point out that mainstream itself involves serious theoretical inconsistencies. The one to which most attention has been paid is the mainstream treatment of capital, where inconsistency completely undermines the whole theoretical edifice built on the principle of substitution, which, it is shown, does not apply to capital (Kurz and Salvadori 2000). John King highlights this critique of mainstream economics in relation to the Sraffian case for pluralism - but a pluralism without mainstream economics. For Sraffians therefore theoretical consistency is so crucial that its violation justifies rejection, even by pluralists.

If it is to be taken for granted that theoretical consistency is desirable, where does that leave heterodox economics, where inconsistencies persist, notably between the micro and macro levels within any one approach? Inconsistencies persist also between theories within heterodox schools of thought, such as Post Keynesian economics, as seen in the debates between the different Post 
Keynesian approaches to monetary theory (see for example Arestis and Sawyer, eds, 2006). There are even more inconsistencies between heterodox schools of thought.

Clearly there are inconsistencies and inconsistencies, and some are more important than others; indeed when is an inconsistency a sign of incoherence and when is it just a difference (see further Dow 1990)? A clue to how to deal with this is given in King's (2008: 11) account of Chick's (2002) justification for not pursuing completely consistent Post Keynesian microfoundations, whose title refers to 'necessary compromise': 'Chick therefore rejected the possibility of impeccably logical microfoundations', which could be provided only at the expense of "the logic of the whole"'. The stumbling block in any effort to develop consistent microfoundations is the fictional nature of the auctioneer. The nature of the theoretical relationship between microeconomics and macroeconomics then is something open to reasoned argument and persuasion rather than definitive logical demonstration.

Consistency takes its meaning from logic, but there is more than one logic on which methodology can be based, and there is more than one sphere of logic. First we consider two main types of logic: classical logic and human logic, as applied to theory. But we cannot go far with this without considering the sphere of application - what is the 'whole' to which Chick refers? In particular we need to think about the justification for using one or other type of logic at the philosophical level - this will be the subject of the following section. 


\section{Logical Consistency: classical and human logic}

It is common to equate logic with classical logic, which has indeed dominated Western thought. This system of logic is deductivist, deriving conclusions by means of deductive logic from premises which are taken to be true. If the logic is correct the conclusions are then also true. If the logic is incorrect this can be proved by identifying a logical contradiction - an inconsistency. Within this type of logic inconsistency can be identified definitively and is something to be eradicated since it undermines the entire argument. Where a body of theory follows classical logic, it takes the form of a deductivist system, all of which is founded on premises which refer to the lowest level, i.e. it is reductionist.

This is the type of logic employed by mainstream economics and which underpinned the drive for microfoundations of macroeconomics: that macroeconomic propositions should be derivable from the axioms of rational optimising behaviour which are taken to be true, or at least 'as if' true. The theoretical system which is built on such principles is a closed system and lends itself to formal mathematical expression. (In terms of the racehorse metaphor, whatever the racecourse and its current condition, there is only one type of horse which is acceptable.) Further, within such a system the notion of consistency is unambiguous and is closely aligned with the notion of rigour. No wonder there is such unquestioning support for consistency as a principle.

The presumed truth of the premises is critical to classical logic. In the case of economics, the axioms of rational choice have been the object of sustained questioning. Within mainstream economics, such questioning (as in the new behavioural economics) is aimed at establishing more robust axioms. But in heterodox economics, the prospect of any axioms being established as true is questioned and an alternative logic preferred in order to deal with the absence of certainty about 
any assumptions. This is the type of logic employed by Keynes, variously termed 'ordinary logic' or 'human logic' (Gerrard 1992). For Keynes (as for Hume) reason (and thus deductivism) was insufficient for justifying belief as the basis for action. Because of the complex, evolving nature of the economic system, we can never expect to uncover true causal mechanisms, far less predict on their basis. Rather than relying on one reasoned argument, he argued that beliefs are more soundly based if they draw on a range of types of argument and/or of language (Harcourt 1984, 1987). Further, since contexts of analysis differ, choice of types of argument and evidence should reflect the problem at hand: 'horses for courses'.

This logic can be characterised, in contrast to the Cartesian/Euclidean character of a system of thought based on classical logic, as Babylonian thought, based on the Babylonian style of mathematics (Dow 2012). This approach builds up knowledge by means of a range of arguments which are incommensurate (otherwise they could collapse into one argument). Thus one line of argument might use the ceteris paribus argument to focus on one sector, treating the rest of the economy as exogenous. Another line of argument might focus on the interrelations between that sector and another with which it interacts, treating all the rest as exogenous. This would seem unexceptional to a mainstream economist, but their expectation would be that the two analyses could then be combined in an overarching formal analysis, derivable from the rationality axioms. Within human logic, rather, the expectation is that different types of argument will help to build up the strands of an argument, but there is no basis for treating any of the provisional assumptions as axioms. In terms of the 'horses for courses' metaphor, we can consider each horse as encompassing a particular combination of characteristics, each characteristic representing one method or line of argument. Schools of thought may emerge around a particular range (a stable) 
of combinations of types of argument within human logic (different horses), providing some structure to what in principle would be endless possibilities (the category 'horse' is bounded).

From a classical logic point of view, the human logic approach is riddled with inconsistencies. But within human logic it is inevitable that different (inconsistent?) assumptions will be used for different purposes. The issue is the domain of application of an assumption, which is universal in the case of classical logic and local in the case of human logic. This follows from the closed nature of a system of classical logic, such that any contradiction undermines the whole system. Herein lies the force of the heterodox critiques of orthodoxy which identify inconsistencies in terms of classical logic, as in the capital controversies. In an open system there will be differences between lines of reasoning and the assumptions on which they are built, but these need not involve inconsistency. Inconsistency is only definitive within any one partial analysis, for example if perfect foresight were assumed for some agents and uncertainty for others within one model. Within human logic it is therefore not legitimate necessarily to regard different assumptions as entailing inconsistency since the domains are different. There is no overarching closed deductive edifice to be challenged by apparent contradiction.

Whitehead (1938: 76) concludes his discussion of consistency as follows: 'Thus inconsistency is relative to the abstraction involved'. A microeconomic theory may involve different assumptions from a macroeconomic theory, but if they are each treated as partial systems rather than part of a formal overarching system, no inconsistency need be involved. There is an important distinction between models (which require provisional closure) and theoretical systems:

'The key is how far the theoretical system is identified with its models. Within an open theoretical system, there is scope for changing the assumptions, boundaries or ceteris 
paribus conditions to suit the theorist's immediate purpose, as for example assuming that long-term expectations are fixed in one model but not in another. Discussion surrounding these models extends beyond the models in order to take account of what has been "kept at the back of one's head". A closed theoretical system on the other hand tends to be identified with its models' (Chick and Dow 2005: 369-70).

Whitehead (1938: 75) had seemed to imply that inconsistency was not an issue within what we now refer to as an open-system mode of thought: ' $[b]$ y means of process the universe escapes from the limitations of the finite. Process is the immanence of the infinite in the finite; whereby all bounds are burst, and all inconsistencies dissolved.' This has echoes of postmodernism, which celebrates paradox as one of its features, something which is anathema to classical logic (and different from the reasoned compromise over consistency in the Post Keynesian approach, for example). But to see the prevalence of process is not to give up on theoretical argument. I have argued elsewhere (Dow 2001a) that postmodernism runs the risk of presenting itself in terms of classical logic, and thus as employing the dual of modernist classical logic, which is absence of logic. In terms of the 'horses for courses' metaphor, there would be no horserace.

Of course postmodernists do in fact employ logic, for example to justify general arguments, but this is inconsistent with the dual of classical logic. Similarly, McCloskey (1986) has shown that mainstream economists aren't consistent either in their use of logic - an example of methodological inconsistency. While classical logic is central to the official discourse in publications, informal, unofficial discourse in fact employs a range of types of argument more in line with human logic. It should not be surprising that deductive logic is insufficient to demonstrate the superiority of one line of argument over another. The failure of the Bourbaki project to 
represent mathematics as a completely closed system provides ample illustration of the problems. Indeed the continuing inconsistency between pure and applied work in mainstream economics can be understood in terms of the primacy of the consistency principle in pure mathematics, when compared to applied mathematics (Weintraub 2002). But even in empirical work, the drive for internal consistency has overridden concerns with realism (Wren-Lewis 2011).

But the implication is that a completely internally consistent closed formal system representing the economy is unattainable, however persistently it is pursued. But in practice the charge of theoretical inconsistency in terms of classical logic has proved to be insufficient for theory rejection, as we have seen by the waiving aside by the orthodoxy of heterodox arguments about inconsistencies with respect to capital, even though such methodological inconsistency is straightforward since the stated primacy of consistency within mainstream economics takes its meaning from classical logic.

It clearly matters whether inconsistency is understood in terms of classical logic or human logic. It is appropriate to critique mainstream economics for theoretical and methodological inconsistency on its own, classical logic, terms. For heterodox economics, a critique on grounds of theoretical inconsistency within the body of theory as a whole (rather than any partial analysis) needs to be expressed in terms of human logic. Similarly methodological inconsistency is only relevant if it is identified in terms of human logic. But to understand what that entails we need to return to Chick's 'logic of the whole'. The discussion above has been straying from issues of methodological consistency into issues of philosophical consistency. We have seen the importance of ontology, or how we understand the subject matter. We turn now to consider philosophical consistency: the logic of the whole. 


\section{Philosophical Consistency}

While King (2008) argues against the notion of theoretical foundations, he does advocate social and philosophical foundations. I understand his discussion of social foundations as referring to ontology and the philosophical foundations as referring to epistemology. What he is arguing therefore is that theorising should not only be consistent with a particular ontology, and also a particular epistemology but that these are both prior to theorising. When heterodox economists argue that the nature of the social world is such that it does not yield lawlike behaviour and thus any prospect of demonstrating which is the best theory to represent it, they are making a consistency argument - not consistency within a closed theoretical system, but consistency between the theoretical system and the nature of the subject matter. (In terms of the "horses for courses' metaphor, it is the understanding of the nature of the racecourse and its current conditions which determines the choice of horse to run.) Thus Lawson (1997) argues for open-system theorising (which employs human logic) to address an open-system reality. Since there is no demonstrably best form of theorising about an open system, as King (2002) explains, there will be a range of open theoretical systems each employing its own range of methods, i.e. pluralism. (Different owners will have a range of horses in their stables, based on their understandings of the nature of the course.)

That each of these systems adopts different ranges of assumptions and methods implies inconsistency in the sense of differences at the methodological and theoretical levels between different approaches. But for heterodox economics there is consistency with the particular opensystem ontology of each system. In contrast, Lawson (1997) points out that the closed-system theorising of mainstream economics is only consistent with a closed-system reality. To the extent 
that many mainstream economists in fact believe the real social world to be open, they are being philosophically inconsistent. (There is only one type of horse to be run, even if the owner knows it to be unsuited to any course on which the race will be run.)

This argument implies that philosophical consistency trumps theoretical consistency (which in any case depends on epistemology including the type of logic employed). The case for pluralism rests on philosophical consistency. Further it would appear that philosophy (ontology and epistemology) should indeed be foundational. I am associated with this view, not least because of the title of my recent book, Foundations for New Economic Thinking, but also because I have long argued for increased awareness of the philosophical assumptions implicit in economic theory and the need to ensure philosophical consistency. So it might seem perverse to raise issues with it. Nevertheless I would like to raise again some issues with a uni-directional version of foundations (see further Dow 2001b).

Everything follows from ontology. Yet our understanding of reality is a complex product of socially-mediated experience. Indeed the philosophy of economics is performative to the extent that our understanding of reality and the corresponding appropriate epistemology can be the result of our assimilation into a mainstream approach to economics. For society at large, the reality may be performative too, to the extent that the media, government and business organisations accept the mainstream account of the real social world and the appropriate way to build knowledge about it. In particular, if mainstream economics succeeds in representing formal mathematical systems as the most rigourous and inconsistency within these systems as a sign of defective science, economists and economic agents alike are encouraged to understand economic behaviour as driven by rational choice and mathematical modelling as the best way to proceed in building up 
knowledge. We have had ample evidence in the financial crisis of this performativity, when financial deregulation, confidence in the capacity for risk assessment and even reregulation took this view, with real consequences. Ontology is then affected by epistemology and methodology.

This reverse causation can also occur in a more constructive way. Where philosophy is foundational, economists may be expected to follow instruction from philosophers, something which mainstream economists in particular have been notably reluctant to do. Even where lip service is paid to philosophy of science, such as the work of Popper or Lakatos, the practice has not been consistent with it (Blaug 1980). Where the argument for focusing on philosophical foundations stands the best chance is where there is significant input from practising economists, not least because practice informs philosophy. This is not just a matter of rhetoric, but a matter of developing methodological principles through practice.

These two arguments may seem like quibbles relative to the important argument for social and philosophical foundations, but they are in fact symptomatic of the particular philosophical foundations of heterodox economics, that the different levels interact and in both directions. Ontology and epistemology are foundational in that they need to be addressed consciously when developing and justifying one's approach. This is not incompatible with acknowledging that, from a systemic perspective, ontology and epistemology are themselves ultimately endogenous.

\section{Communication and Consistency}

King (2002) notes the inconsistencies between the three arguments for pluralism he sets out. But I agree with his conclusion that pluralism does not mean methodological or theoretical uniformity, 
even when making the case for pluralism - in fact the point of pluralism is that it does not. Rather pluralism entails communication between different approaches. There is sufficient philosophical commonality - essentially each approach is identified with an open-system ontology out of the many possibilities and an open-system epistemology out of the many possibilities.

Communication itself requires some level of consistency, which different ontologies and epistemologies might be thought to belie. But the philosophical foundations provide the solution. For a closed-system ontology and epistemology, meanings are fixed and precise such that there should be no scope for communication difficulties. Indeed it is one of the arguments for mathematical formalism that it ensures just such a commensurability. Mathematics is regarded as a particularly precise language, but its precision is internal and does not extend to application. Incommensurability arises for mainstream theory outside the system in terms of the subject matter which is excluded because of the mathematical method, but more generally in terms of the translation of formal terms into real experience, i.e. in application to the real world (see Harcourt 1984 for an account of the history of this line of argument). Since mainstream methodology is exclusively mathematical there is no solution other than to treat application as an art requiring a different methodology which is inconsistent with the methodology which produced the pure theory which is to be applied (Colander 2002). In order to avoid methodological contradiction, the solution has been to separate off the area of application where meanings lose their precision and inconsistencies may arise.

For open-system epistemologies, identification and definition of categories is provisional within an evolving environment. Context is of critical importance, requiring adaptation of theories and concepts. Not only may different strands of argument employ different 'languages' (Harcourt 
1984), but verbal language has particular advantage in being vague, allowing overlapping meanings which allow conversation. The issue of the precision (or otherwise) of language arose within the debates between rationalism and common sense philosophy early in the twentieth century in Cambridge (see Coates, 1996 and Davis's, 1999, review article). While rationalist argument aimed for precision, this precision was less clearly appealing when arguments were applied to the real world. Harcourt (1992: 276) suggests that Marshall made the choice in favour of real-world application at the cost of precision: 'it is better to be vaguely right than precisely wrong' (an expression acquired from W Carr, via Shove). The vagueness of ordinary language, corresponding to ordinary logic, has the virtue of allowing greater scope for correspondence between reasoned argument and the real world. The scope for ambiguity allows for change in the subject matter, because meaning of verbal language is more flexible than the meaning of mathematical terms or data series. The meaning of verbal terms further tends to be complex rather than singular, incorporating a range of connotations.

But even in mathematics and the physical sciences terms are vague in the sense that their meaning has changed over the years. The metaphors we use in economics benefit from their vagueness. Game theory for example draws on the metaphor of the game and the cluster of meanings attached to it (Coates, 1996: chapter 2). Similarly, the metaphor of the market benefits from its vagueness. That is what allows Becker to extend market analysis into the family context. It may be that the market is precisely defined for the purposes of deductive theory, in terms of preferences defined in a precise way with respect to the abstract concept of rational economic man. But what the rhetoric literature has taught us is that how we actually understand and discuss this theory and these concepts draws on our wider understanding of the world. This is made possible by the vagueness of our use of what are intended to be precise terms. 
But vagueness is only helpful where there is significant overlap of meaning. Where meanings are very different the use of a common language can impede communication. The confusion caused by the different meanings of rationality is a case in point, just as here we are focusing on distinctions between different meanings of 'consistency'.

\section{Conclusion: Post Keynesian Economics and Consistency}

King (2008) makes clear the quite different (methodological and theoretical) positions taken on microfoundations within heterodox economics. If heterodox economics is to progress within the hoped-for pluralist economics, then it is important to address differences which imply incoherence. But shared philosophical foundations and the vagueness of language should facilitate communication and therefore debate. We have also argued that theoretical 'inconsistencies' are inevitable within heterodox economics given the open-system approach and the human logic by which it is pursued. It is consistency with ontology which is the most important.

This issue of consistency within heterodox economics, and particularly within Post Keynesian economics has come up before, implicitly in comparison with mainstream economics which emphasises internal consistency. In 1988, Hamouda and Harcourt published an account of three strands within Post Keynesian economics and posed the question of how far this school of thought is coherent. This paper elicited a response from Backhouse (1988) which in effect focused on the coherence of mainstream economics in comparison to Post Keynesian economics. Because Post Keynesian economics does not prioritise theoretical consistency - indeed argues against doing so

- then it inevitably qualifies as a degenerating Lakatosian research programme (because of what 
Backhouse perceives as ad hocery). Alternatively, he suggests that a Kuhnian interpretation would classify Post Keynesian as immature relative to mainstream economics. It is clear that the conclusion that Post Keynesianism is deficient was based on the charge of theoretical and methodological inconsistency in its classical logic sense.

There was a further round of debate when Walters and Young (1996) published a set of arguments that Post Keynesianism lacked coherence, but this time referring also to different accounts of philosophical foundations. This paper drew a strong response from Arestis, Dunn and Sawyer (1999) who explained the prevalence of commonalities in what Walters and Young had identified as differences. The possibility of differences at the philosophical level requires serious attention. The pluralist methodology of Post Keynesian economics requires that there be multiple strands of reasoning, involving different methods and generating different partial theories. But a school of thought is defined by its shared methodology, which requires a shared ontology and epistemology.

In considering the future of Post Keynesian economics, or indeed heterodox economics more generally, it is therefore important that we distinguish between inconsistencies within partial analyses, within methodologies and between these and the underlying philosophical foundations. The philosophical position does not allow for 'anything goes'. John King has drawn our attention to one important example of apparent inconsistency: the stance on microfoundations. For him it is consistency between the philosophical foundation on the one hand and methodology and theory on the other which is of primary importance. He has argued for a movement in the direction of more consistency between theory at the micro level and the macro level. But the guiding principle is consistency of each of micro and macro theory with the nature of the subject matter, rather than necessarily with each other. 
At the same time as pursuing consistency in this sense, it is important not to be distracted by other charges of inconsistency which do not in fact make sense within a pluralist methodology or opensystems epistemology. But the challenge is greater for such an approach relative to the simplicity and clarity of the consistency criterion in classical logic. The argument has to be made on a caseby-case basis for particular segmentations of analysis into the multiple pluralist strands, based on consistency with understanding of the real context at hand, and then judgement needs to be applied in forming a conclusion based on this pluralist analysis. Consistency is important within partial analyses, but inconsistency in the sense of differences between analyses is to be expected, as long as it does not involve inconsistency with philosophical foundations.

In seeking to summarise the case for this analysis of consistency, it is hard to put it better than the concluding statement in Hamouda and Harcourt (1988: 24-5):

'What we have tried to show is that, within the various strands which we have discerned and described, there are coherent frameworks and approaches to be found, though obviously there remain within each unfinished business and unresolved puzzles. The real difficulty arises when attempts are made to synthesize the strands in order to see whether a coherent whole emerges. Our own view is that this is a misplaced exercise, that to attempt to do so is mainly to search for what Joan Robinson called "only another box of tricks" to replace the "complete theory" of mainstream economics which all strands reject. The important perspective to take away is, we believe, that there is no uniform way of tackling all issues in economics and that the various strands in post Keynesian economics differ from one another, not least because they are concerned with different issues and often different levels of abstraction and analysis. 
An important implication of the above conclusion is that the policies which may be rationalized by post Keynesian analysis are very much geared to concrete situations, the historical experiences and the sociological characteristics of the economies concerned. More generally, this approach which was that, for example, of Keynes, Kalecki, Joan Robinson and Arthur Okun, sometimes and most appropriately, has been dubbed the “horses for courses” approach.'

As John King puts it, within any partial analysis, each horse must 'have four legs and a jockey and proceed anti-clockwise around the course' and further that 'all four legs must be pointing in the same direction'. There needs to be consistency in terms of the choice of methods to use (the horse) and ontology (the understanding of the nature of the racecourse and it current conditions) if there is to be a good chance of generating useful analysis (winning the race). Different open-system ontologies justify different choices of method (different types of horse). Relying exclusively as does mainstream economics on one method regardless of ontology (one type of horse chosen, e.g. for its aesthetic appeal) cannot reasonably be expected to succeed. But here the metaphor breaks down. Were it the case that all agreed on epistemology and thus on the criteria for success (the rules of the race), we would end up with a monist choice of approach (a clear winner). Rather the metaphor applies to the stage of planning for the race and placing bets - even under uncertainty, practicing economists must adopt one approach or another within the plurality on offer. We support the stable we judge to have the best range of horses to address the course as we understand it, and the ability to make the best choice of horse for particular conditions. 


\section{References}

Arestis, P, Dunn, S P and Sawyer, M (1999) 'On the coherence of Post-Keynesian economics: a comment on Walters and Young', Scottish Journal of Political Economy, 46 (3): 339-45.

Arestis, P and Sawyer, M, eds (2006) Handbook of Alternative Monetary Economics. Cheltenham: Edward Elgar.

Backhouse, R (1988) 'Comment on Hamouda and Harcourt', Bulletin of Economic Research 40 (1): $35-41$.

Blaug, M (1980) The Methodology of Economics, second edition 1992 (Cambridge: Cambridge University Press).

Chick, V (2002) 'Keynes's theory of investment and necessary compromise', in S C Dow and J Hillard, eds, Keynes, Uncertainty and the Global Economy: Beyond Keynes, vol. 2. Cheltenham: Edward Elgar, pp. 55-67.

Chick, V and Dow, S C (2005) 'The Meaning of Open Systems', Journal of Economic Methodology, 12(3): 363-81.

Coates, J (1996) The Claims of Common Sense. Cambridge: Cambridge University Press.

Colander, D (2002) 'The Lost Art of Economics', Journal of Economic Perspectives, 6(3): 191-8. 
Davis, J B (1999) 'Common Sense: A Middle Way between Formalism and Post-structualism?', Cambridge Journal of Economics, 23: 503-13.

Dow, S C (1990) Beyond Dualism, Cambridge Journal of Economics, 14 (2): 143-58, reproduced in J B Davis, ed., Recent Developments in Economic Methodology, vol. II. Cheltenham: Edward Elgar, 2006, pp. 261-75 and S C Dow, Foundations for New Economic Thinking: a selection of essays. London: Palgrave, 2012.

Dow, S C (1997) 'Methodological Pluralism and Pluralism of Method', in A Salanti and E Screpanti, eds, Pluralism in Economics: Theory, History and Methodology. Cheltenham: Edward Elgar, pp. 8999.

Dow, S C (2001a) 'Modernism and Postmodernism: A Dialectical Process', in S Cullenberg, J Amariglio and D F Ruccio, eds, Postmodernism, Economics and Knowledge. London: Routledge, pp. $61-76$.

Dow, S C (2001b) 'Methodology in a Pluralist Environment', Journal of Economic Methodology, 8(1): $33-40$.

Dow, S C (2007) 'Variety of Methodological Approach in Economics', Journal of Economic Surveys 21 (3): 447-19.

Dow, S C (2008) 'Plurality in Orthodox and Heterodox Economics', Journal of Philosophical Economics 1(2): 73-96.

Dow, S C (2012) 'The Babylonian Mode of Thought', in J King, ed., The Elgar Companion to Post Keynesian Economics, second edition, Cheltenham: Edward Elgar. 
Gerrard, B (1992) 'Human Logic in Keynes's Thought', in P Arestis and V Chick, eds, Recent Developments in Post-Keynesian Economics. Aldershot: Edward Elgar.

Hamouda, O F and Harcourt, G C (1988) 'Post Keynesianism: From Criticism to Coherence?'. Bulletin of Economic Research, 40 (1): 1-34.

Harcourt, G C (1984) 'Reflections on the development of economics as a discipline', History of Political Economy', 16: 489-517.

Harcourt, G C ([1987]1992) 'The legacy of Keynes: theoretical methods and unfinished business', in D A Reece, ed., The Legacy of Keynes. San Fransisco: Harper \& Row, reprinted in C Sardoni, ed., On Political Economists and Modern Political. Economy: Selected Essays of G C Harcourt. London: Routledge, pp. 235-49.

Harcourt, G C (1996) 'How I do economics', in S G Medema and W J Samuels, eds, Foundations of Research in Economics: how do economists do economics? Cheltenham: Edward Elgar, pp. 93102.

Harcourt, G C (1992) 'Marshall's Principles as Seen through the Eyes of Gerald Shove, Dennis Robertson and Joan Robinson', in C Sardoni, ed., On Political Economists and Modern Political. Economy: Selected Essays of G C Harcourt. London: Routledge, pp. 265-80.

King, J E (2002) 'Three Arguments for Pluralism in Economics', Journal of Australian Political Economy 50 (December): 82-7. Reprinted in post-autistic economic review 23 (5), article 2, 2004.

King, J E (2008) 'Microfoundations?', presented to the FMM Conference, Berlin. 
King, J E (2012) The Microfoundations Delusion: Metaphor and Dogma in the History of Macroeconomics. Cheltenham: Edward Elgar.

Kurz, H D and Salvadori, N (2000) 'On critics and protective belts', in H D Kurz and N Salvadori, eds, Understanding 'Classical’ Economics: Studies in Long-Period Theory. London: Routledge, pp. $235-58$.

Lawson, T (1997) Economics and Reality. London: Routledge.

McCloskey, D N (1986) The Rhetoric of Economics. Brighton: Wheatsheaf.

Walters, B and Young, D (1997) 'On the Coherence of Post-Keynesian Economics', Scottish Journal of Political Economy, 44 (3): 329-49.

Weintraub, E R (2002) How Economics Became a Mathematical Science. Durham, NC: Duke University Press.

Whitehead, A N (1938) Modes of Thought. Cambridge: Cambridge University Press.

Wren-Lewis, S (2011) 'Internal consistency, price rigidity and the microfoundations of macroeconomics', Journal of Economic Methodology, 18 (2): 129-46.

' This paper has benefitted from helpful comments and suggestions from Geoff Harcourt and from an anonymous referee. 